\title{
$\mathrm{C}^{-} \mathrm{I}$ CONGRESO \\ INTERNACIONAL \\ SOBRE \\ LF_O FOTOGRAFÍA
}

Congreso Internacional sobre Fotografía

UPV, 5 y 6 octubre 2017

Doi: http://dx.doi.org/10.4995/CIFo17.2017.6895

ISBN: 84-84-978-84-9048-604-7

\section{El Fondo Fotográfico Atín Aya, claves para una interpretación.}

Pablo Martínez-Cousinou

Universidad de Sevilla, mpmartinez1@us.es

\begin{abstract}
The photographic archive Atín Aya, keys to an interpretation.

This communication aims to make known the Atin Aya photographic archive, its inventorying and cataloging process as well as analyzing its main thematic axes. Atin Aya extensively documented the social reality of Andalusia during the last quarter of the twentieth century, a period characterized by the leap into modernity and the international competition of Spain: European integration, Expo 92, Olympic Games, etc.

His legacy houses abundant visual documentation of the creation and first years of Andalusian Regional Administration, the urban transformation of Seville on the occasion of the Universal Exhibition, the policies of preservation of the vernacular Andalusian heritage, the economic, social and infrastructure advances that integration brought with it, but at the same time, Aya knew how to collect, with an extraordinary sensitivity and anthropological view, those disappearing cultural forms that development relegated to ever more minority scenarios, paying special attention to the culture of work and its people. His work allows us to dialectize modernity in Andalusia with a critical eye, as well as to establish connections between the social function of documentary practice and the construction of democracy in our country. The funds of the Atin Aya photographic archive will be available soon in open access at www.atinaya.com, facilitating any subsequent consultation or research about it.
\end{abstract}

Keywords: Atín Aya, Documentary photography, Photographic archives, Andalusia

\footnotetext{
Resumen

Esta comunicación pretende dar a conocer el Fondo Fotográfico Atín Aya, su proceso de inventariado y catalogación así como analizar sus principales ejes temáticos.

Atín Aya documentó extensamente la realidad social de Andalucía durante el último cuarto del siglo XX, un periodo caracterizado por el salto a la modernidad y al concurso internacional de España: integración europea, Expo 92, Juegos Olímpicos, etc... Su legado alberga abundante documentación visual de la creación y primeros años de la autonomía andaluza, de la transformación urbanística de Sevilla con motivo de la Exposición Universal, de las políticas de preservación del patrimonio vernacular andaluz, de los avances económicos, sociales y en infraestructuras que aquella integración trajo consigo. Pero al mismo tiempo, Aya supo recoger, con extraordinaria sensibilidad y mirada antropológica, aquellas formas culturales en
} 
desaparición que el desarrollo relegaba a escenarios cada vez más minoritarios, prestando especial interés a la cultura del trabajo y a su paisanaje.

Su obra nos permite dialectizar la modernidad en Andalucía con una mirada crítica, a la vez que establecer conexiones entre la función social de la práctica documental y la construcción de la democracia en nuestro país. El Fondo Fotográfico Atín Aya estará disponible en un futuro próximo a través de la página web www.atinaya.com.

Palabras clave: Atín Aya, Fotografía documental, Archivo fotográfico, Andalucía.

\section{Introducción}

Joaquín Aya Abaurre (1955-2007), más conocido como Atín Aya, es uno de los máximos referentes de la fotografía reciente en Andalucía. Aya desarrolló un extenso trabajo de documentación de la realidad social de esta comunidad durante las décadas finales del siglo XX. Concretamente, la acotación temporal comprende el período que va desde 1981, año de inicio de su etapa profesional, hasta 2007, año de su fallecimiento; un periodo histórico que abarca desde los inicios de la democracia española, y el consiguiente avance de la reivindicación identitaria regional, hasta el cambio de siglo, el desarrollo de la globalización y la llegada de la sociedad de la información. Un arco temporal caracterizado por el salto a la modernidad y al concurso internacional de España: integración europea, Expo 92, Juegos Olímpicos, etc... Su legado alberga abundante documentación visual de la creación y primeros años de la autonomía andaluza, de la transformación urbanística de Sevilla con motivo de la Exposición Universal, de las políticas de preservación del patrimonio vernacular andaluz, de los avances económicos, sociales y en infraestructuras que aquella integración trajo consigo.

A lo largo de los últimos cinco años, se ha llevado a cabo un proceso de ordenación, inventariado y catalogación de la producción fotográfica de Atín Aya con la finalidad de poner en valor y hacer accesible al público interesado esta obra de gran valor patrimonial para la memoria regional y nacional ${ }^{1}$. Siguiendo la línea trazada, en la actualidad, se está trabajando en la creación de una base de datos en la que poder acceder en un futuro a los fondos digitalizados ${ }^{2}$.

El la presente comunicación se describen, por un lado, las fases del proceso de inventariado y catalogación llevado a cabo y, por otro, se plantean algunas de las claves y características más representativas del conjunto de la obra para su mejor comprensión.

\section{Objetivos}

La presente comunicación se plantea, de este modo, dos objetivos principales:

Por un lado, dar a conocer y poner en valor la existencia del Fondo Fotográfico Atín Aya (FFAA): sus características, estructura, alcance y situación actual.

Por otro, definir las temáticas abordadas y algunas de las características más representativas de su producción fotográfica, extraídas del análisis de su obra, con las que dar muestra de su significación en el marco cultural y social de Andalucía.

Esta comunicación se inscribe, asimismo, dentro de un trabajo de investigación en curso sobre la obra de Atín Aya, en el que se lleva cabo un análisis de la misma a la luz de los Estudios Visuales.

\section{Descripción del Fondo Fotográfico Atín Aya}

\footnotetext{
${ }^{1}$ El proceso ha sido coordinado por María Aya, responsable del FF.AA. y ha contado con el asesoramiento de Diego Carrasco, amigo y editor del autor, y el trabajo de la conservadora Gabriella de Florio y de Rosa Hurtado.

2 La titularidad privada del Fondo Fotográfico Atín Aya encuentra un obstáculo a la hora de poder financiar la totalidad del proceso de digitalización del mismo, dados los elevados costes en mano de obra que elllo conlleva. Este hecho plantea la necesidad de abrir procesos de interlocución con la administración pública u otras entidades privadas para la búsqueda de financiación con tal fín.
} 
El fondo fotográfico de Atín Aya se encuentra situado en Sevilla capital, en el estudio de los pintores Manolo Salinas y Pepe Barragán. Se compone de negativos y diapositivas en los tres formatos, a saber, paso universal $(35 \mathrm{~mm})$; medio formato $(6 \times 7 \mathrm{~cm})$ y gran formato $(9 \times 12 \mathrm{~cm})$, si bien, la mayor parte el conjunto de la misma es en negativo blanco y negro en pequeño y medio formato. Por tratarse de un fondo fotográfico contemporáneo su estado de conservación es óptimo, por lo que las intervenciones en el proceso de conservación han sido mínimas. Éstas han consistido básicamente en la limpieza de todas las unidades del fondo fotográfico y el archivo de los distintos soportes en fundas y cajas acondicionadas. La conservación de las copias de época, sin embargo, sí ha requerido de mayor atención ya que éstas han estado menos protegidas que los negativos y las diapositivas y más expuestas a las condiciones de humedad. Se tratará sobre este aspecto más adelante en un epígrafe posterior.

En el proceso de ordenación se han separado tres bloques: la producción fotográfica del autor; el archivo privado, conjunto de fotografías familiares desde el siglo XIX y un tercer bloque denominado "Otros" en el que se han conservado copias de otros autores, pósters e información de exposiciones propias, calendarios fotográficos, así como otro tipo de egodocumentos tales como libretas y anotaciones sueltas con información relativa a los reportajes realizados.

A la hora de iniciar el proceso se diferenció entre el "inventario antiguo", una parte del fondo fotográfico ordenada por Atín Aya, relativa a los primeros 1988 negativos de $35 \mathrm{~mm}$ y 350 negativos de medio formato, todos con sus respectivas hojas de contacto, lo que facilita enormemente el acceso a los contenidos de los mismos, y por otro lado, el resto de producción fotográfica, referida principalmente a los últimos años y a trabajos realizados por encargo.

El inventariado final ha dado como resultado:

A) Producción de AA.

Negativos de $35 \mathrm{~mm}$ en blanco y negro: 2171 carretes ( 78156 unidades).

Negativos de medio fromato en blanco y negro: 440 carretes ( 4400 unidades aprox.)

Negativos de gran formato en blanco y negro: 534 unidades.

Diapositivas en $35 \mathrm{~mm}$ : 8285 unidades.

Diapositivas en 6 x $7 \mathrm{~cm}$ y 9 x $12 \mathrm{~cm}$ : 1483 unidades.

Copias fotográficas en diferente tamaño: 4116 unidades.

B) Archivo privado.

Compuesto por fotografías del álbum familiar, queda a su vez dividido en copias antiguas (920 unidades) y copias coetáneas a Atín Aya, en gran número realizadas por él mismo. (1168 unidades). 


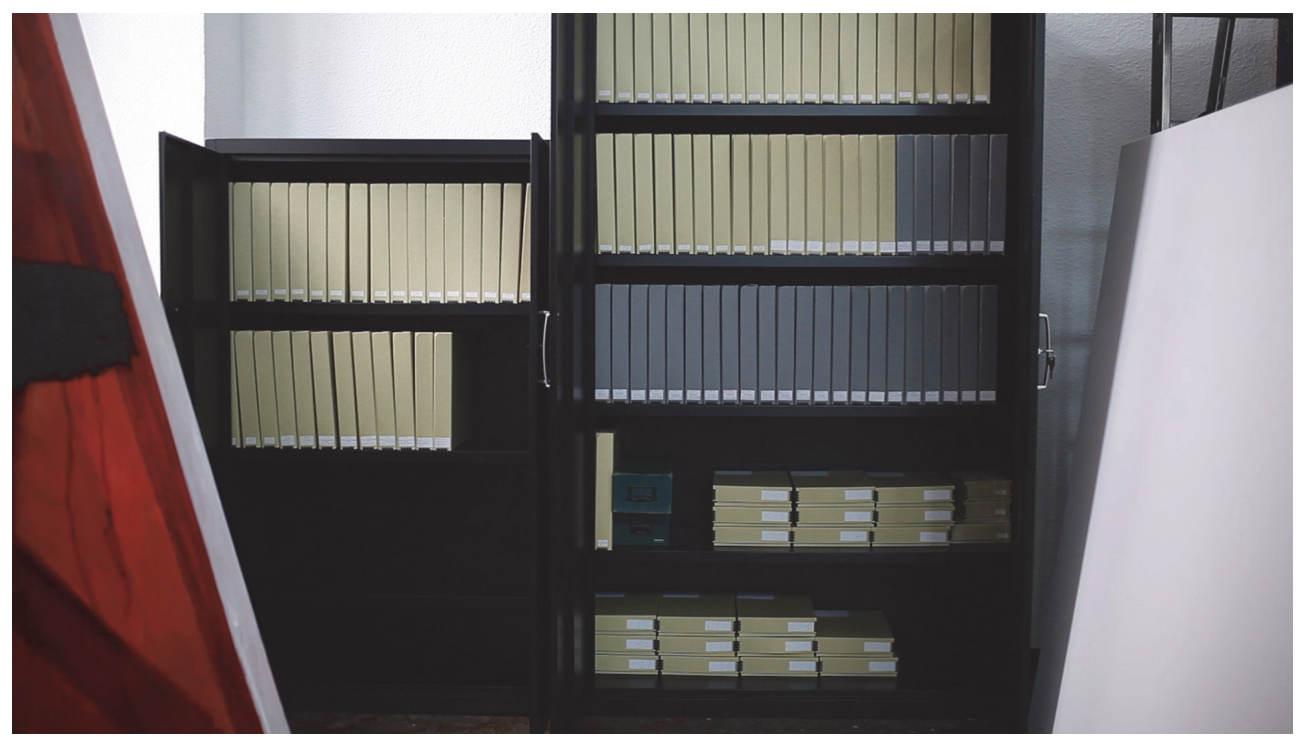

Fig. 1 Muebles para negativos, diapositivas y copias de hasta 24 x $30 \mathrm{~cm}$ del Fondo Fotográfico Atín Aya. Estudio del pintor Manolo Salinas en Sevilla capital.

\subsection{Sistema de almacenamiento}

Para el almacenamiento de los fondos fotográficos de AA se han utilizado finalmente cuatro muebles de archivo construidos a medida. Dos para el archivo de negativos, diapositivas y copias de hasta 24 x $30 \mathrm{~cm}$. y dos planeros de diferente tamaño para el archivo de las copias fotográficas de mayor tamaño.

Estos muebles y planeros reúnen las condiciones necesarias para la conservación de material de archivo, siendo ignífugos, si bien sería conveniente en el futuro el trasladarlos a un lugar donde las condiciones de humedad sean controladas.

Asimismo las cajas utilizadas y las fundas para copias, negativos y diapositivas, son de PH neutro, libres de ácido, y transparentes, lo que posibilita mirar directamete el negativo sin necesidad sacarlo de la funda y manipularlo.

\subsection{Proceso de inventariado y catalogación}

El proceso de conservación e inventariado del FFAA se inició en 2007, si bien se ha desarrollado principalmente a lo largo de los últimos cinco años. El objetivo final perseguido ha sido, en primer lugar, el de limpiar, clasificar y ordenar los distintos documentos del fondo fotográfico para garantizar la conservación de los originales y, en segundo lugar, llevar a cabo un proceso de inventariado y descripción seguido de un proceso de catalogación que dé como resultado una una base de datos desde la que acceder a los contenidos del fondo.

El proceso comenzó a partir de la numeración de las distintas cajas y etiquetando de cada fotografía con un número de inventario. Inicialmente los datos se fueron insertando en una base de datos de excel, que progresivamente se fue enriqueciendo, en la medida de lo posible con la información correspondiente a cada rollo de película y a cada negativo concreto, actividad para la que ha sido especialmente necesaria la colaboración de Diego Carrasco, escritor, amigo y editor de Atín Aya.

Tras consultar varios archivos y colecciones privadas no se han seguido finalmente criterios normalizados de catalogación ni sistemas de descripción estandarizados para fotografía sino que se ha creado un sistema de clasificacion ex-profeso que se adaptara a las condiciones propias del fondo a partir de una serie de términos de búsqueda y temáticas específicas. 
La base de datos consta de siete secciones:

1) Información general, que posibilita el sistema de búsqueda mediante Número de registro, Título y Descripción.

2) Características básicas, en la que se puede discriminar en la búsqueda según Álbum ( si se conoce previamente la ubicación aproximada), Año, Mes, Orientación, Tipo de soporte, Tono, Formato/Tamaño y tipo de Película. Al final de la sección, la opción Serie, permite desplegar un cuadro en el que aparecen las "series" mas'destacadas del autor, a saber: Arte, Artistas y Amigos, Andaluces, Composiciones, Cortijos, Fiestas tradicionales, Marismas, Moda, Otros, Parques y jardines, Prensa, Privado, Reportaje, Semana Santa, Sevillanos, Toros, Viajes, UIMP ( Universidad Internacional Menéndez y Pelayo); e igualmente conocer si existe Contacto del registro buscado, si hay copia en Papel baritado y si está Digitalizado.

3) Localización permite acotar la busqueda por contexto Geográfico, País, Provincia y Localidad.

4) Selecciones diferencia entre si el registro pertenece a una selección realizada por el Autor o por Terceros, así como si forma parte de los contenidos utilizados para Web, Exposición o Publicación. Permite asimismo añadir Datos de la Exposición y Datos de Publicación.

5) Categorías. En este apartado es donde se delimitan las principales temáticas abordadas en la obra de AA, permitiendo marcar una o varias de las casillas entre las siguientes: Escenas, Retratos, Paisaje Urbano, Paisaje Natural, Oficios, Arquitectura, Rural, Niños, Fauna, Privado, Desnudos y Deporte.

6) En Conservación se incluyen datos referidos a la Ubicación Inicial y la Ubicación final, el Estado de conservación, la Fecha de control última así como otros Detalles que puedan aportar información para la búsqueda.

7) Por último en Imágenes, se indica si se cuenta con imagen digitalizada del registro y se posibilita su visionado.

A la hora de realizar una consulta, la base de datos muestra los resultados destacando en la barra superior el número de identificación, el número de registro, el título, el año de producción, la serie a la que pertenece el registro, la ubicación en la que éste se encuentra y la última fecha de actualización de la información sobre el mismo.

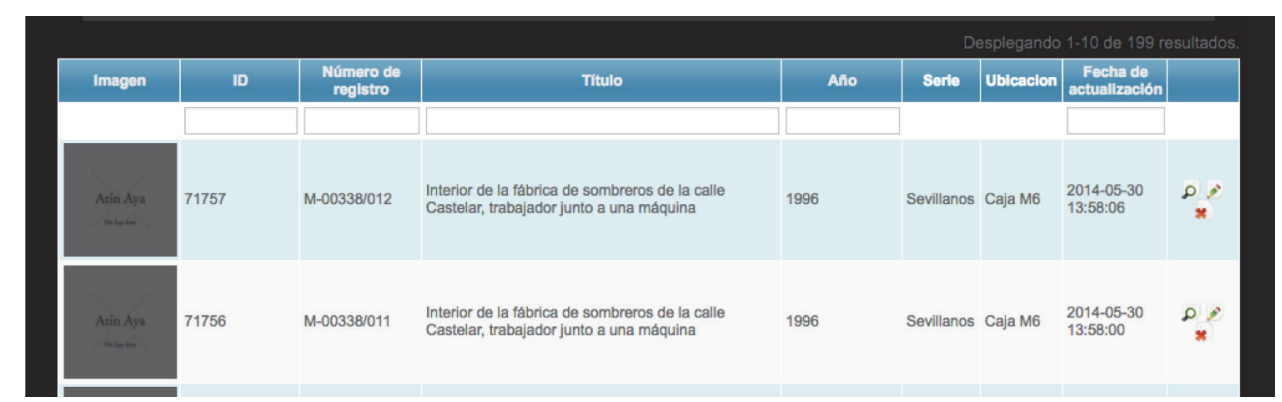

Fig. 2 Aspecto del interfaz de la base de datos. Resultados obtenidos en una consulta en la que se han introducido los términos "Formato: $6 \times 7 \mathrm{~cm}$ y Categorias: "Paisaje Urbano" + "Oficios". 


\section{Pautas para una interpretación de la obra de Atín Aya.}

\subsection{Principales publicaciones monográficas.}

Tres son las obras monográficas publicadas por Atín Aya en vida, en orden cronológico Imágenes de la Maestranza, Las Marismas del Guadalquivir y Sevillanos ${ }^{3}$. Imágenes de la Maestranza (1996) será, a diferencia del resto de publicaciones, un encargo para documentar a lo largo de dos Ferias de Abril la Real Maestranza de Caballería de Sevilla. Es de destacar que no es el ritual en sí el objeto sobre el que se centrará Aya, sino por el contrario, lo hará en los personajes anónimos que conforman la vida que se desarrolla entre bastidores, que hacen posible la celebración y el espectáculo pero que se mantienen al margen del reconocimiento social y de la fama. "Yo no soy taurino y los toros me interesan como un evento, como concentración humana. Lo he fotografiado todo menos la lidia, lo que se vive fuera del ruedo, como si yo fuera un espectador del ambiente" (Ferrand, 1996).

Las Marismas del Guadalquivir (2000), es un extenso trabajo de documentación desarrollado en profundidad a lo largo de cinco años sobre el territorio y las formas culturales en desaparición de esta región del bajo Guadalquivir que abarca parte de las provinvias de Sevilla, Huelva y Cádiz. Una obra especialmente significativa y singular por la contundencia y calidad de los paisajes y los retratos ${ }^{4}$.

Sevillanos (2001), será una colección de imágenes de la ciudad y sus ciudadanos tomadas a lo largo de los últimos veinte años. ${ }^{5}$

Con posterioridad vio la luz, en el año 2010, una obra póstuma: Paisanos (Aya, 2010), en la que se muestra un retrato colectivo de Andalucía compuesto por imágenes en su mayoría anteriormente inéditas, que constituyen en cierto modo una continuación a la anterior Sevillanos. Como se puede observar, será el interés por el ser humano, por las personas el motivo principal de su obra personal y el retrato su género predilecto.

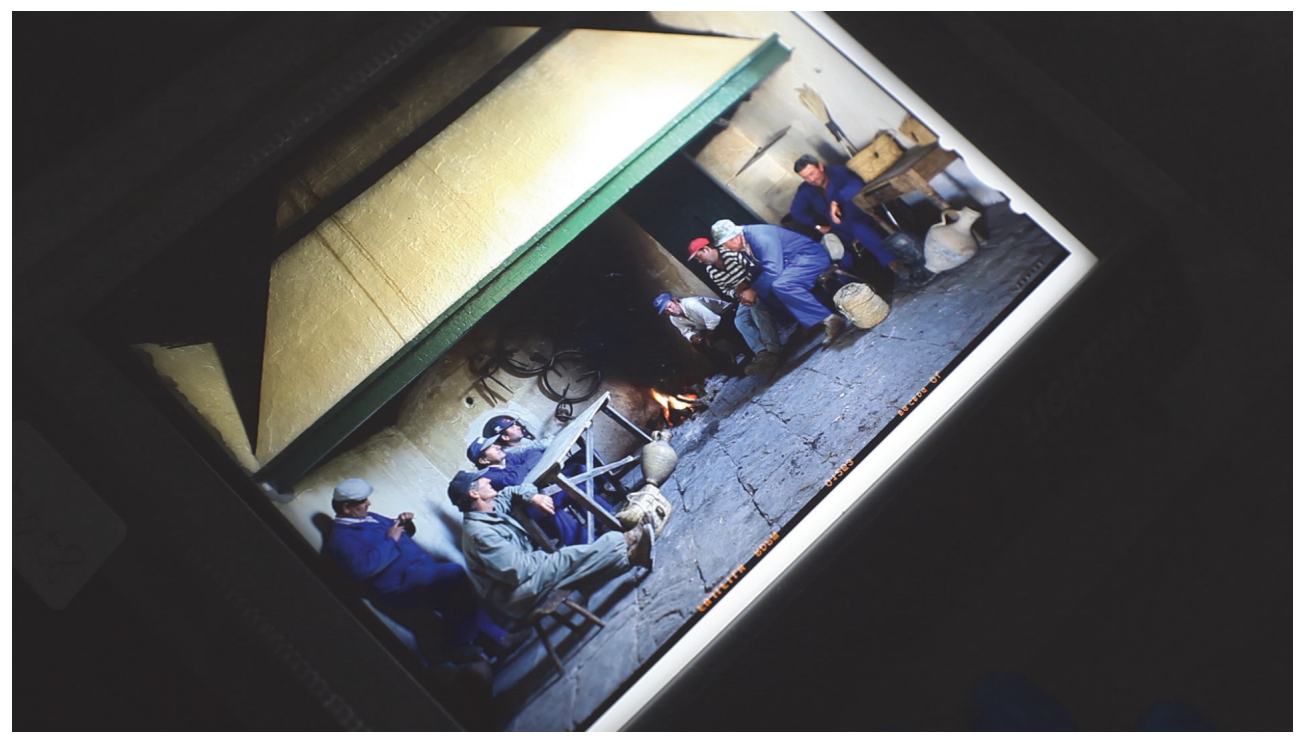

Fig.3 Labores de limpieza del fondo fotográfico. En la imagen: Trabajadores. Gañanía del Chorreadero Viejo. San José del Valle, Cádiz. 2001. Diapositiva $9 \times 12 \mathrm{~cm}$. perteneciente a la serie Paisanos.

\subsection{Las principales temáticas abordadas}

\footnotetext{
${ }^{3}$ Las tres obras citadas se encuentran en la actualidad descatalogadas.

${ }^{4}$ Como curiosidad, esta obra sirvió de inspiración al director Alberto Rodríguez y al guionista Rafael Cobos para la realización de la galardonada película Isla Mínima (2014).

${ }^{5}$ Para mayor información sobre esta monografía y sobre la documentación de la ciudad véase: Martínez-Cousinou (2016) "Atín Aya y la Fotografía de Arquitectura".
} 
Si bien el espectro de temáticas abordadas a lo largo de su carrera es amplio, como se muestra en la pestaña "Categorías" de la base de datos del FFAA, "arquitectura, retrato, paisaje urbano, paisaje natural, desnudo", etc. cabe destacar una serie de ejes temáticos que, de manera general, son apreciables en el conjunto de su obra.

En primer lugar hay un interés manifiesto a lo largo de su obra por la realidad del Sur peninsular; el Sur como concepto identitario, como categoría. Un sur asociado a Andalucía pero que se extiende de alguna manera en sus visitas a Cuba, Brasil o Marruecos. Un sur periférico y popular que ha padecido el retraso económico y político. En el caso de Andalucía, AA se centra en documentar aquellas realidades premodernas, que se encuentran a destiempo con el presente. Le interesan los resquicios de un pasado en pleno proceso de transformación, vestigios de una situación histórica de subdesarrollo que aparecen por los intersticos de las costuras de la modernidad. En este sentido, Aya busca lo intemporal, aquello que no refleja los cambios que introduce la modernidad. En esta concepción y representación del tiempo se dirimen, como veremos en el epígrafe siguiente, algunas de las claves de la práctica documental en AA.

Delimitado "el sur" como acotación espacial, el motor que mueve a Atín Aya a documentar la realidad parece ser, dada la continua presencia en su obra, el interés por el elemento humano, por el retrato de los conciudadanos, de los paisanos. El interés por recoger las múltiples formas y los rostros de lo vivible. Las personas aparecen inscritas en un entorno que nos da pistas del contexto social del que forman parte. Una aproximación a la realidad sin cosméticos, una práctica del retrato directo y sin artificiosidad en el que recupera en muchas ocasiones los tiempos y procesos de la fotografía de principios del siglo XX, retratos detenidos, previsualizados, realizados con medio o gran formato.

Estos dos vectores confluyen a su vez en un interés por lo popular y por el universo del trabajo. La documentación de una cultural laboral, eminentemente rural y asociada a oficios artesanales en desaparición. Aquí cabe hablar de interés por la subalternidad, interés por dar un espacio de representación a esas formas de trabajo menos visibles, o a personajes menos "normalizados", un interés por mostrar la amplitud, riqueza y variedad de la diferencia.

Un quinto elemento sería el territorio, subsidiario en cierto modo del citado interés por las personas. En la obra de AA el territorio aparece más como contexto de los personajes que como motivo en sí. Un territorio explorado en los múltiples viajes realizados por Andalucía para fotografiar encargos de prensa, institucionales para la Junta de Andalucía o para proyectos personales y que va a ser representado como marco, como espacio habitado, como escenario en el que la vida se desarrolla y transcurre.

Andalucía, como marco conceptual y territorio, el retrato, unido a lo popular, y el universo laboral, principalmente subalterno y rural, van a ser las temáticas más recurrentes en su obra. A este sucinto mapeo temático hay que unir su interés por las formas culturales en desaparición y su peculiar concepción temporal de lo documental que se tratará en el siguiente epígrafe.

\subsection{Sobre la concepción de la práctica documental en Atín Aya}

El conjunto de la obra de AA participa, formalmente, de la retórica del documental clásico, aquel caracterizado por contar con una composición cuidada, luz natural, corrección tonal, riqueza de gama, nitidez y calidad en el detalle y estar realizado, en gran medida, en blanco y negro. Atín Aya entronca como epígono con la generación de autores que desarrollaron el reportaje de autor de orientación antropológica a partir de los años setenta, el grupo compuesto por Fernando Herráez, Cristina García Rodero, Koldo Chamorro, Ramón Zabalza y Cristóbal Hara, fotógrafos que coincidirán en documentar una España que, de espaldas a la modernidad, iba desapareciendo ${ }^{6}$. AA pertenece ya a una segunda generación de universitarios que no han vivido la Guerra Civil, a una generación que no ha sufrido la etapa más dura de autarquía y regresión de la dictadura.

\footnotetext{
${ }^{6}$ Estos cinco fotógrafos participarán en la significativa exposición Vanishing Spain inaugurada en el International Center of Photography de Nueva York en 1991. Celebrada en el marco de los programas con motivo de la celebración de la Exposición Universal de 1992, en la muestra se representa el punto de inflexión entre la España moderna y desarrollada que se abre a la comunidad internacional y los vestigios de una otra España que, aunque presente, mantiene tradiciones y costumbres de una época pasada, cuya existencia, como el título de la muestra indica, desaparece con celeridad.
} 
En sus inicios Aya bebe de la concepción de la fotografía de los fotoperiodistas de la Transición. Una nueva generación que incorporó los aires de la democracia a la práctica de la profesión fotoperiodística y a sus muchas nuevas cabeceras y que estaba representada por autores como Jordi Socias, Luis Magán, José Manuel Navia, Paco Elvira, Pilar Aymerich, Pablo Neustadt, Víctor Steinberg, Sigfried Casals, entre un largo etcétera.

Serán algunos de estos fotoperiodistas los que constituyan su gran influencia, sus referentes y concepción inicial del fotoperiodismo, con cuyas imágenes trabajará Aya como laborista en el Photocentro de Madrid, en el que se formó brevemente al terminar sus estudios de Psicología en la Universidad de Granada. Tras la etapa de formación en Madrid, Aya regresará a Sevilla donde comenzará a colaborar en prensa diaria, primero brevemente para $\mathrm{ABC}$ y al poco tiempo para la recién inaugurada edición de Diario 16 Andalucía. Iniciaba así sus casi tres décadas de producción fotográfica, en las que la realidad de la comunidad autónoma andaluza se convertirá en el principal eje temático.

Recuperando las palabras de Reyes Mate en el prólogo a La Herencia del Olvido, es posible establecer conexiones entre esta concepción clásica de la fotografía documental como forma de alumbrar aquellas realidades menos "normalizadas" o difundidas, de la que participa Atín Aya, y "la pregunta por la significación política, moral y epistémica de lo olvidado"7 . Una concepción de la práctica documental sensible a la diferencia, clásica en el sentido de la fotografía reformista norteamericana de los años treinta, de los Walter Evans o Dorothea Lange y al mismo tiempo muy acorde con la realidad sociopolítica de los años posteriores a la dictadura en España.

Quizá la singularidad de la obra de AA se encuentre, en gran medida, en su condición de práctica situada; una fotografía realizada desde la periferia cultural y meridional de España y, a su vez, sobre las realidades más periféricas de ésta. Su constancia en la documentación de la realidad andaluza y en la incidencia en el registro de estas formas culturales en desaparición va a ser una de las señas definidoras de su obra.

La capacidad de dialectizar el tiempo histórico, de testimoniar un tiempo que cambia rápidamente y construir memoria; la capacidad para detener la mirada y registrar esa detención; la capacidad de poner en relación dialógica temporalidades distintas y al mismo tiempo cohetáneas va a ser una característica principal de su producción. Esa capacidad de particiar en un presente dinámico y al mismo tiempo mirar hacia atrás para registrar lo que no tiene espacio en la agenda y temporalidad mediática.

Posiblemente en esta concepción de la práctica documental radique la diferencia de la obra de AA en relación al discurso visual entonces hegemónico, lo que hace diferente su obra y la dota de gran singularidad. Su producción juega a desplazar el foco de atención. Aya no documenta realidades lejanas, sino que en una suerte de desplazamiento escópico se implica con realidades próximas, si bien, temporalmente y socialmente diferentes.

La visualidad que se destila de este modo de la obra de Aya puede ser descrita, a modo de resumen, como una lectura horizontal, enormemente democrática en esa horizontalidad, del tejido histórico en que vive. Una lectura horizontal que, sin pretender responder a trazados conceptuales o analíticos, muestra una cierta distancia reflexiva, testimonial y directa que no busca la emoción forzada y que evidencia una sincronía con un imagiario propio, una previsualización que se mantiene homogénea. Una mirada ajena a los tópicos. Una suerte de hilo de Ariadna, que contribuye a una mejor guía por los años finales del siglo XX en que tiene lugar la llegada de la modernidad, de la globalización y de la sociedad de mercado a Andalucía.

Es en esta relación con el tiempo en la que se dirime la singularidad del trabajo documental de AA. Una relación con el tiempo inherente a la propia práctica documental pero que en la obra de AA cobra una dimensión nueva al poner en juego realidades que pertenecen a realidades temporales distintas, al atravesar diversas temporalidades, al evidenciar las heterocronías o multiples temporalidades que cohexisten en un mismo presente, al incidir a la documentación de lo intemporal.

Es en este eje definido por los polos de premodernidad y modernidad en Andalucía, en cuya tensión dialéctica se desarrollan los procesos de democracia y de globalización donde se encuentran las claves del trabajo de AA y su concepción de lo documental.

\footnotetext{
${ }^{7}$ MATE, R. (2008). La herencia del olvido.Madrid. Errata naturae editores. P. 23
} 


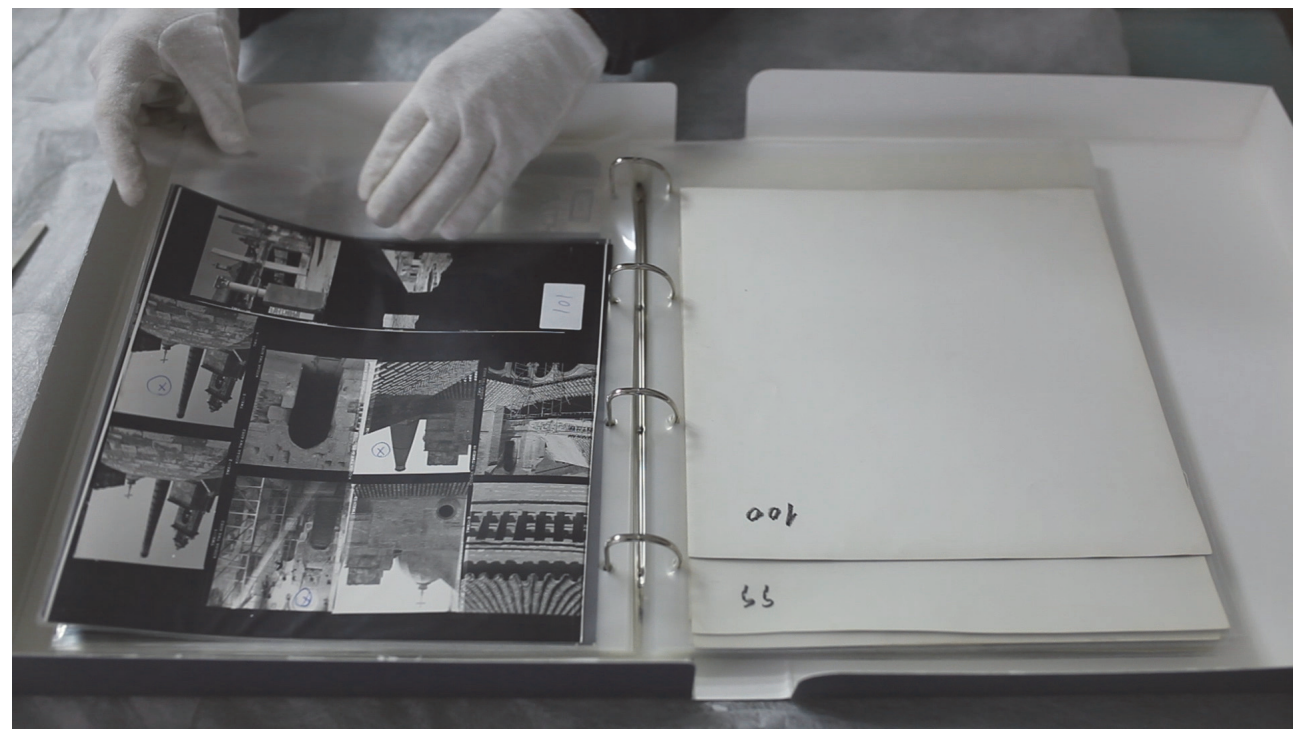

Fig.4. Hoja de contacto. Negativos 6 x $7 \mathrm{~cm}$. Documentación del proceso de rehabilitación del Monasterio de Santa María de las Cuevas en la Isla de la Cartuja con motivo de la Exposición Universal de 1992.

\section{Conclusiones y líneas abiertas de investigación}

En el desplazamiento que se produce en una obra fotográfica al pasar de su condición de representación a su condición de archivo, de su uso informativo y o expresivo o artístico a su uso como fuente documental hay una traslación semántica, una nueva categoría que conlleva implicaciones relacionadas con la forma de entender el patrimonio y por extensión la cultura.

Esta traslación, esta redimensión del significado de la obra se debe a que sobre ella se sella un valor añadido que hace referencia a su condición de legado, de documento de la cultura, de material memoria sobre el que es posible regresar para repensar las claves y formas culturales que nos anteceden.

El conjunto de avatares, acontecimientos y experiencias acumuladas a lo largo de la trayectoria de producción fotográfica de un fotógrafo toman un sentido de cuerpo unitario, de conjunto orgánico, al constituirse fondo fotográfico. Hay una subjetividad que recorre y sobrevuela el conjunto de la producción.

La constitución del Fondo Fotográfico Atín Aya como "institución" cultural de la memoria, representa así una muy significativa aportación patrimonial para la identidad, la cultura y la memoria de Andalucía dadas las singulares características de la propia obra así como la especial relevancia del período histórico en el que ésta se inscribe, a cuya mejor comprensión ésta, al mismo tiempo, contribuye.

Su digitalización, pendiente en la actualidad de poder completarse, a expensas de encontrar apoyos externos para sufragar su financiación, ofrecerá un enorme potencial como recurso educativo y cultural, con distintas aplicaciones formativas, informativas y de explotación en las industrias culturales y del entretenimiento. Al mismo tiempo, facilitará el desarrollo de futuras líneas de investigación relacionadas con la Historia reciente de la fotografía documental y el fotoperiodismo en Andalucía, el análisis de la Imagen y Memoria reciente de Andalucía, la evolución de la función social de la práctica documental en el contexto español y su relación con la democracia, o bien sobre la propia obra inédita de Atín Aya. 


\section{Referencias}

AYA, A. (1996). Imágenes de La Maestranza. Javier Rubiales (Ed.) Sevilla. Real Maestranza de Caballería.

(2000). Las Marismas del Guadalquivir. Mauricio D’Ors (Ed.) Sevilla. Fundación Caja San Fernando.

(2001). Sevillanos. Sevilla. Fundación Focus-Abengoa.

(2010). Paisanos. Sevilla. Fundación Cajasol.

(2013) Atín Aya. Madrid. La Fábrica.

BREA, J.L. (2010) Las tres eras de la imagen: imagen-materia, film, e-imagen. Madrid, Akal.

CINTADO, L.(1987). "Colección privada: Iñaki Gabilondo". Diario 16 Andalucía. Sevilla, 1987, 19 de enero, pp. 38-39.

DIDI- HUBERMANN, G. (2011) Ante el tiempo. Historia del arte y anacronismo de las imágenes. Buenos aires, Adriana Hidalgo editora.

FERRAND, P. (1996). "De perfil: Atín Aya". Diario ABC. Sevilla, 1996, 18 de octubre, p. 44.

GARCÍA CARCELES, M. (2016) "Estrategias de gestión y difusión de colecciones en el marco de las nuevas tecnologías" En Patrimonio Cultural de España. Fotografía y patrimonio a debate. (2016). N 11.Madrid: Ministerio de Educación, Cultura y Deporte.

GARCÍA MARTÍN, F. (2000). Entrevista con Atín Aya. En Única de Andalucía. Verano de 2000. Sevilla.

HERNÁNDEZ-NAVARRO. M.A. (Ed.) (2008) "Heterocronías. Tiempo, Arte y Arqueologías del presente". Murcia, CENDEAC.

MARTINEZ-COUSINOU, P. (2016). "Atín Aya y la fotografía de arquitectura". En Inter photo arch. Congreso Internacional Inter-fotografía y arquitectura. Interferencias. Pamplona: Universidad de Navarra. Disponible en http://hdl.handle.net/10171/42445 [Consulta: 10 de septiembre de 2017]

MATE, R. ( 2008). La herencia del olvido.Madrid. Errata naturae editores.

MIRA PASTOR, E. (1991). La vanguardia fotográfica de los años setenta en España. Alicante: Instituto de Cultura Juan Gil Albert.

ORELLANA GONZALEZ, C. (1991). Índice de las memorandas del Archivo Municipal de Jerez de la Frontera. Jerez de la Frontera: Ayuntamiento de Jerez.

VV.AA. (2015). Plan Nacional de Conservación del Patrimonio Fotográfico. Madrid.

CANAL SUR. Tierra y Mar. 2016. "Atín Aya en la marisma del Guadalquivir". Youtube

https://www.youtube.com/watch? v=5XH522WtGQ\&ab channel=TierrayMar\%26EspacioProtegidoCanalSur[ $[\mathrm{Co}$ nsultado el 12 de septiembre de 2017] 